\title{
Violência infantil: uma reflexão bioética como norteadora de ações concretas que garantam o resguardo do direito e da integridade do menor
}

\section{Child violence: a bioethic reflection guiding concrete actions to guarantee the minor's rights and integrity}

\section{Ana Beatriz Ferreira Paiva}

Pontifícia Universidade Católica do Rio Grande do Sul, Porto Alegre, Rio Grande do Sul, Brasil.

biafepaiva@ig.com.br

\section{Anelise Crippa Silva}

Pontifícia Universidade Católica do Rio Grande do Sul, Porto Alegre, Rio Grande do Sul, Brasil.

anecrippa@gmail.com

\section{Giovana Palmieri Buonicore}

Pontifícia Universidade Católica do Rio Grande do Sul, Porto Alegre, Rio Grande do Sul, Brasil.

gibuonicore@hotmail.com

\section{Anamaria Gonçalves dos Santos Feijó}

Pontifícia Universidade Católica do Rio Grande do Sul, Porto Alegre, Rio Grande do Sul, Brasil.

agsfeijo@pucrs.br

Resumo: Este trabalho propõe uma reflexão teórica sobre um dos aspectos prioritários de políticas públicas em países democráticos ocidentais: a violência e o abuso sexual contra crianças e adolescentes. Apresenta legislação internacional e nacional como instrumentos de resguardo do direito e da integridade dessas crianças e relaciona os princípios bioéticos com as ações propostas para garantir a dignidade dos menores agredidos. Fundamenta a necessidade de acompanhamento psicológico às vítimas após a violência sofrida.

Palavras-chave: Abuso sexual infantil. Violência intrafamiliar. Bioética. Vulnerabilidade.

Abstract: This work proposes a theoretical reflection about one of the most important 
aspects of the public politic in occidental democratic countries: the violence and sexual abuse against children and teenagers. International and national legislation are showed like guard instruments of the law and integrity of these children and relate the bioethics principles with proposed actions to guarantee the dignity of the attacked child. Expose the necessity of the psychological treatment for the victims after the violence they suffered.

Keywords: Children sexual abuse. Intrafamilial violence. Bioethics. Vulnerability.

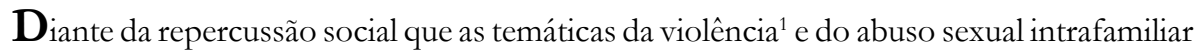
contra crianças e adolescentes trouxeram, sentiu-se a necessidade de propor uma análise sobre o acompanhamento psicológico a essas vítimas em nosso cotidiano.

Os danos físicos, psíquicos e morais infringidos a essas pessoas vulneráveis não tem sido efetivamente minimizados através de tratamento e acompanhamento dos mesmos, sendo considerado um problema social significativo e havendo, por isso, a necessidade de ações concretas que busquem sanar essa falha.

Faz-se necessário contextualizar o histórico da violência em nível mundial e nacional para que se entenda como ela se instaurou em nossa cultura brasileira ao longo dos tempos.

O Estatuto da Criança e do Adolescente de 1990 (ECA), a Constituição Federal de 1988 (CF) e a Declaração dos Direitos Humanos e Bioética de 2005 (Unesco), ao tratarem da garantia dos direitos, das formas de negligência, de violência, de exploração, da inviolabilidade da integridade física, psíquica e moral da criança e do adolescente, são bem específicos em relação à prevenção e à busca e punição do culpado. Porém, esses documentos não fornecem subsídios em relação ao tratamento e ao acompanhamento de curto, médio e longo prazo para as vítimas.

Busca-se neste trabalho chamar a atenção para a orientação de tratamento psicológico a ser oferecido às vitimas de violência e a continuidade do mesmo após o abuso sofrido pela criança e adolescente, para que estas sejam capazes de socializarem-se sem conflito.

\section{Histórico da violência contra a criança e o adolescente}

\section{Contexto Mundial}

\footnotetext{
1. A OMS define violência como o "uso intencional de força ou poder físico de fato ou como ameaça, contra si mesmo, outra pessoa ou grupo ou comunidade, que cause ou tenha muita probabilidade de causar lesões, morte, danos psicológicos, transtornos de desenvolvimento ou privações” (23).
} 
A violência contra a criança e o adolescente esteve presente durante toda a história da humanidade. A relação de dominação e disciplinamento dos menores como vítimas de maus tratos e descaso por parte da sociedade, observada desde os mais antigos registros, e que estão arraigados a nossa cultura, se contrapõe a uma nova perspectiva de apoio e proteção integral a essas crianças e adolescentes que se tenta impor contemporaneamente (1).

Acerca dessa trajetória histórica, Aristóteles, filósofo grego, acreditava na pedagogia como função do estado, onde na falta das virtudes naturais se faz necessário incluir bons hábitos pela educação, aparecendo, portanto, a pedagogia como um tipo de política. A pedagogia e a moral são colocadas no mesmo patamar. A moral como uma política aplicada aos adultos e, por sua vez, a pedagogia aplicada a crianças e adolescentes. Assim diz ele: "como cada família é uma parte da pólis, assim a virtude da parte deve ser considerada em relação ao todo. É necessário construir uma educação das crianças e das mulheres fixando o olhar na constituição da cidade, já que importa para o bem do estado que as crianças e as mulheres sejam cheias de ardor pelo bem" (2).

Platão (3) nos ensina que o modelo educacional que ocorre por meio de uma formação básica evolui até os estudos filosóficos. Nela, as crianças deveriam ser retiradas dos pais e enviadas para o campo para que se desvencilhassem de influência corruptora da família. A formação em idade militar era válida para Platão. Lá, os jovens deveriam permanecer dos 17 aos 20 anos, onde seriam submetidos a testes para saber que carreira seguir. Dentro desse esquema de seleção, os mais dotados iniciariam os estudos superiores. Dentre os reprovados, os melhores se destinariam ao exército e os outros a diversas profissões e ofícios civis.

Para Constantino (306 d.C.), imperador romano, a adolescência durava até os 50 anos, quando então se iniciava a velhice. Apesar dessas limitações cronológicas, a caracterização da infância como estágio oposto ao da idade adulta não existia (4).

No Iluminismo (séculos 17 e 18), houve uma grande explosão de ideias sobre o assunto. Com a industrialização e o crescimento urbano acelerado, os indivíduos se tornaram anônimos. A partir do século 19, a adolescência passou a ser delimitada, identificada, esquadrinhada e controlada. As meninas que, ao contrário dos meninos, até então não tinham uma instrução formal, passaram a recebê-la. As famílias ricas começaram a criticar os colégios (internatos, na maioria) porque a instrução formal oferecida gerava maus hábitos morais e resolveram retirar seus filhos dessas escolas. Para as famílias pobres e camponesas, entretanto, a instituição escolar era encarada como uma possibilidade real das crianças terem um futuro melhor. Ficou então dividido o ensino formal da seguinte maneira: externato para o rico e internato para o pobre (1).

No século 20, surgiram as políticas de proteção de crianças e adolescentes em 
consonância com a ampliação dos conhecimentos de psicologia baseados na teoria dos pensadores teóricos do desenvolvimento humano. Conforme o referido autor, esses teóricos, embora com posicionamentos distintos, contribuíram para a construção de uma concepção de infância e para a adaptação do processo educativo.

\section{Contexto Nacional}

O Brasil, enquanto colônia de Portugal, acatava suas leis e ordens, pois dependia econômica, política e administrativamente desse país. A igreja e o estado andavam juntos, unindo a conquista armada e a religião. Os padres jesuítas se preocupavam em catequizar e batizar as crianças índias e posteriormente incorporá-las ao trabalho. Os religiosos fundavam casas de recolhimento ou casa para meninos e meninas índias, pois não aceitavam a matança dos índios pelos portugueses. As crianças índias eram separadas da sua comunidade e a elas era imposto seguir os costumes e normas do cristianismo, tais como casamento religioso e outros dogmas, com o intuito de introduzi-las na visão cristã do mundo (5).

Os filhos nascidos fora do casamento - produtos da miscigenação entre brancos, índios e negros -, estavam fadados ao abandono; raros eram os filhos ilegítimos que não eram abandonados. Essas crianças eram deixadas nas portas das casas e, muitas vezes eram molestadas por animais como, por exemplo, ratos e porcos, gerando problemas sanitários. Pensando principalmente nessa situação de saúde pública, o governo propôs duas medidas: a coleta de esmolas na comunidade e a internação das crianças. Para esconder essa situação ilegítima e preocupante para os governantes, foi implantada a Roda, que tinha por objetivo recolher as crianças abandonadas. Entretanto, muitas morriam por falta de condições das instituições ou por desinteresse da Corte (6).

Com o intuito de minimizar os custos com as crianças abandonadas, as Câmaras Municipais, que também tinham a responsabilidade de cuidá-las, criaram impostos para arrecadar fundos com este fim e também prestaram assistência a muitas crianças, aceitando seu estabelecimento em casas de famílias em troca de pagamento (1).

As instituições privadas e semioficiais cuidavam dos pobres, favorecendo os ricos, isto é, encaminhando as crianças ao trabalho precoce, transformando-as em futuros subalternos e incentivando até o trabalho escravo (5).

\section{Criação de uma justiça nacional para menores}

A crescente criminalidade de menores no início do século 20 começou a preocupar juristas e congressistas, que entenderam ser importante oferecer um tratamento 
diferenciado para estes jovens, diferente do ofertado aos delinquentes adultos. Este tratamento tinha como objetivo salvar o menor do ambiente perigoso, propondo uma nova justiça para a infância a fim de corrigir desvios de comportamento.

As ações do governo atenderam a uma cronologia de eventos criados a partir da história e das necessidades de assistência à criança e ao adolescente (7): em 1902, o Congresso Nacional discutia a implantação de uma política de "assistência e proteção aos menores abandonados e delinquentes"; em 1903, foi criada a Escola Correcional 15 de Novembro; em 1923, foi autorizada a criação do Juizado de menores; em 1924, criou-se o Conselho de Assistência e Proteção aos Menores e o Abrigo de Menores e; em 1927, toda essa legislação foi consolidada no primeiro Código de Menores.

No Código de 1927 ficou estabelecida a distinção entre abandonados e vadios, determinando que indivíduos maiores de 14 anos e menores de 18 anos fossem submetidos a um processo penal especial, ficando nas mãos do juiz estabelecer as sanções, segundo sua avaliação da boa ou má índole dos que eram julgados e os encaminhamentos a serem feitos para seu disciplinamento. Este Código de 1927 estabelecia também cuidados quanto às questões de higiene da infância, da delinqüência, da vigilância pública sobre a infância - incluída a amamentação -, dos abandonados e dos maltratados, levando até a destituição do pátrio poder. $\mathrm{O}$ menor de 14 anos não era mais submetido ao processo penal e, se o maior de 16 e menor de 18 cometessem algum crime, deveriam ir para a prisão de adultos em lugares separados desses. O papel do juiz era buscar a regeneração do menor pra reintegrá-lo a sociedade (1).

No governo de Getúlio Vargas, 1937-1945, foram criadas as delegacias de menores, que recebiam os meninos encontrados na rua e considerados suspeitos de vício e crime. O Serviço Nacional de Assistência aos Menores (SAM) criado em 1941 e vinculado ao Ministério da Justiça e Negócios Interiores, tinha como objetivo eliminar a ameaça dos meninos "perigosos e suspeitos". Essa instituição usava a repressão ao invés da ação educativa. A Igreja Católica criticou tal instituição, pois as crianças eram violentadas, surradas e torturadas e ainda apresentavam instalações em péssimas condições de uso (1).

Nessa mesma época criou-se o Departamento Nacional da Criança (DNCr), que lutou contra as "criadeiras", mulheres que cuidavam dos menores, e que, devido à pobreza e à falta de condições de higiene, acabavam por propiciar o aparecimento de diversas doenças nas crianças. O DNCr estimulou a amamentação, a vigilância dos lactários e implantação de creches. Após o golpe de Estado ocorreu a sua extinção.

Com a centralização do poder e o Congresso Nacional controlado, os governadores passaram a ser nomeados, em nome da segurança nacional. Foi criada, em 1964, a Fundação Nacional do Bem-Estar do Menor (Funabem), com a missão de diminuir o processo de marginalização, objetivo que não foi alcançado, pois, durante a ditadura, 
acentuou-se a exclusão social, ou seja, a marginalização do menor pela pobreza da família, pela exclusão da escola, pela necessidade de trabalho e pela situação de abandono.

$\mathrm{Na}$ Assembléia Constituinte de 1986, devido à mobilização da sociedade e de alguns setores do Estado e da própria Funabem, e também da necessidade de se desenvolver novas concepções que colocassem as crianças como sujeitos de direitos, foram incluídos na Constituição Federal de 1988 os artigos 227 e 228, que tratam dos direitos da criança. O Estatuto da Criança e do Adolescente, sancionado pelo Presidente da República em 13 de julho de 1990, também incluiu tal medida (7).

A história nos mostra que a criança e o adolescente por muito tempo não eram considerados sujeitos de direitos, não existindo, por isso, uma preocupação com a dignidade, a autoestima e a qualidade de vida desses jovens (5).

\section{Estatuto da Criança e do Adolescente}

O Código Penal Brasileiro vigente, promulgado em 07 de dezembro de 1940, apresentou em seu artigo 27 a inimputabilidade absoluta até os 18 anos de idade. A Carta Magna de 1988, antevendo a Convenção das Nações Unidas de Direito da Criança, elencou em seus artigos 227 e 228 os princípios basilares da Doutrina da Proteção Integral e sacramentou a inimputabilidade do menor de 18 anos.

Nessa época, o adolescente e a criança eram considerados meros objetos de intervenção no mundo adulto, os quais só poderiam fazer valer seus direitos se representados ou assistidos pelos pais ou responsáveis legais. Com a promulgação da Constituição Federal de 1988 este paradigma se alterou, recebendo os menores de 18 anos uma ampla gama de garantias que poderiam ser exercidas frente ao Estado, à sociedade e à família.

Através da lei no. 8.069 de julho de 1990 foi promulgado o Estatuto da Criança e do Adolescente. O ECA veio regular o tratamento aos menores de idade e classificou como criança os indivíduos com idades entre 0 e 12 anos incompletos e como adolescentes aqueles com idades entre 12 a 18 anos completos. Cabe ressaltar que são três os sistemas trazidos pela doutrina para fixar os critérios que determinam a inimputabilidade penal ou a culpabilidade diminuída, quais sejam: o biológico, psicológico e biopsicológico.

O Código Penal Brasileiro adotou o sistema biopiscológico, uma vez que, por meio dele, a responsabilidade só é excluída se o agente, em razão de enfermidade ou retardamento mental está no momento da ação, incapaz de entendimento ético-jurídico e autodeterminação. Assim, apenas a falta de sanidade mental ou de maturidade (hipótese da menoridade de 18 anos) é que, no direito penal brasileiro, podem conduzir ao reconhecimento da inimputabilidade, excludente de culpabilidade. 
Nesse contexto, o ECA entrou em vigor para garantir esses direitos elencados na Constituição indistintamente a todas as crianças e adolescentes, independentemente das condições sociais, familiares ou econômicas. Para tanto, previu a aplicação de duas espécies de medidas: a socioeducativa e a de proteção.

Além das medidas socioeducativas, prevê o artigo 101 do ECA a adoção de medidas protetivas, aplicáveis sempre que houver risco pessoal ou social e também na hipótese de direitos e garantias fundamentais de crianças e adolescentes serem violados. Um adolescente acometido de uma doença mental não poderá receber medida socioeducativa - que possui caráter pedagógico, sendo submetido à medida de proteção determinada no artigo 101, inciso V, do ECA, devendo ser internado em hospital ou submetido a tratamento ambulatorial.

\section{As formas da violência}

A agressão infantil intra ou extrafamiliar é, sem sombra de dúvida, uma situação que gera um sério conflito moral e que exige um repensar ético sobre ações concretas que podem e devem ser tomadas com o intuito de garantir a proteção a esses indivíduos vulneráveis, que são as crianças e os adolescentes.

A violência intrafamiliar, segundo Araújo, designa aquela que ocorre na família e que envolve parentes que vivem sobre o mesmo teto ou não, embora ela seja mais comum entre pessoas que convivem cotidianamente. É, atualmente, umas das prioridades das políticas públicas de muitos países democráticos do ocidente a erradicação também dessa forma de violência, por ser reprovável moralmente e por ir de encontro aos direitos, deveres, normas e princípios éticos fundamentais como a dignidade e/ou vulnerabilidade da pessoa humana e o respeito à autonomia das pessoas envolvidas na ação (8).

$\mathrm{O}$ abuso intrafamiliar - que pode ser praticado tanto por pais ou responsáveis, quanto por parentes mais próximos dos vitimizados (irmãos, tios, avós, dentre outros) -, na maioria das vezes é difícil de ser registrado por causa do vínculo afetivo e econômico e por ameaças da parte do abusador e de outros membros da família. No abuso extrafamiliar é importante conhecer o grau de proximidade entre o abusador e o vitimizado, pois este pode ser muito ligado à vítima como um vizinho, professor, amigo da família, entre outros (7).

Para Souza e Mello Jorge (9) a violência intrafamiliar é considerada uma das formas mais agressivas e cruéis, gerando danos físicos, morais, sexuais e podendo chegar até a morte.

Segundo Santos (7) e Faleiros (1), a violência pode ser classificada da seguinte forma: violência física, psicológica e sexual. A violência sexual está classificada em abuso sexual 
e exploração sexual comercial. Os autores colocam que a violência sexual e psicológica é também uma violência física, pois normalmente é acompanhada pelo medo, terror, submissão, espanto e sofrimento psíquico. A violência psicológica é uma relação de poder desigual entre adultos dotados de autoridade e crianças e adolescentes dominados.

Faleiros (1) diferencia a violência física da violência psicológica, colocando que a segunda não deixa traços visíveis no corpo, mas destrói a autoestima e a autoimagem do violentado, refletindo no comportamento da criança e do adolescente e podem ser tipificadas em atentado violento ao pudor, corrupção de menores, sedução e estupro.

A violência sexual pode acontecer de várias formas: por contato físico, ou seja, carícias não desejadas, penetração oral, anal ou vaginal com o pênis ou objetos, masturbação forçada, dentre outros; e sem contato físico, por exposição obrigatória a material pornográfico, exibicionismo e uso de linguagem erotizada em situação inadequada (7).

O abuso sexual contra crianças e adolescentes é um relacionamento interpessoal sexualizado, privado, de dominação perversa, mantido em silêncio e segredo que é usado para gratificação de um adulto ou mesmo de um adolescente mais velho, baseado numa relação de poder (10). Segundo Furniss (11) e Perrone e Nannini (12), nos abusos sexuais repetitivos, a criança é mantida vitimizada, pois se vê aprisionada e envolvida em uma armadilha da qual não pode e nem sabe se livrar. Essa dominação sexual exercida por adultos é perversa e pode ser incestuosa ou não, heterossexual ou homossexual. Sua ocorrência pode ser verificada nos mais diferentes lugares onde haja segurança para o abusador, normalmente ambientes fechados tais como: residências, consultórios, igrejas, internatos, hospitais, escolas e inclui formas diferentes e variadas de relações abusivas.

A situação que envolve as crianças e os adolescentes poderia ser modificada e o trauma minimizado se houvesse apoio psicológico e assistencial para essas vítimas infantis pelo tempo que fosse necessário.

Santos (7) ressalta os dois pilares explicativos da violência sexual intra e extrafamilliar: o incesto e a pedofilia. Incesto é a relação amorosa entre pessoas de mesmo sangue, principalmente naqueles casos em que o matrimônio é proibido por lei. Este tipo de violência vem acontecendo em praticamente todas as sociedades e culturas desde a antiguidade até a modernidade. Nogueira (13) define a pedofilia, dentro de um conceito social, como sendo a atração erótica por crianças que pode ser elaborada no terreno da fantasia ou se materializar em atos sexuais com meninos e meninas. Segundo o Código Penal Brasileiro, o incesto praticado por adultos contra menores de 14 anos é considerado violência sexual, logo, é crime independente de ser aplicada a força física.

Luci Pfeiffer e Edila Pizzato Salvagni (14) mostram que o abuso sexual pode ser identificado por meio de sinais físicos e corporais, servindo como provas materiais na formulação de um processo criminal. Sinais de comportamento/sentimentos, mudanças 
de hábitos e alteração no desempenho e na freqüência escolar também são fatores a serem considerados.

São diversas as variáveis que podem gerar conseqüências em relação ao abuso sexual: idade do início do abuso, duração do abuso, graus de violência ou ameaça da violência, diferença de idade entre a pessoa que cometeu o abuso e a criança que o sofreu, grau de proximidade da pessoa que cometeu o abuso e a criança, graus de sigilo sobre o fato ocorrido, presença e ausência de figuras parentais (1).

\section{Os princípios bioéticos e a agressão infantil}

A busca de parâmetros na sociedade plural moderna para estabelecer tratamento, por meio da discussão multidisciplinar, para as crianças e a própria violência a elas infringida têm lugar dentro da Bioética. Esta ciência constitui, na verdade, uma área que busca a aplicação de princípios morais estudados na ética, mas aplicados às situações desafiadoras e conflitantes do cotidiano (15). A Enciclopedya of Bioetbics conceitua o verbete "bioética" como "o estudo sistemático das dimensões morais - incluindo visão, decisão e normas morais - das ciências da vida e dos cuidados da saúde, utilizando uma variedade de metodologias éticas num contexto multidisciplinar" (16) caracterizando a grandeza desta área de estudo.

A Bioética busca, essencialmente, um agir humano que aprimore a dignidade e a qualidade de vida e que culmine na apreciação de valores humanos (17). Para que isto seja alcançado, é mister que se trabalhe para erradicar a agressão ao menor e para minimizar os prejuízos morais advindos desta violência, via de regra, intrafamiliar.

A criança é indivíduo vulnerável tanto moral como legalmente. O Estatuto da Criança e do Adolescente, que trata especificamente deste segmento da comunidade, manifesta a preocupação com o nascimento e desenvolvimento integral desses jovens e busca o reconhecimento dos mesmos, como pessoas com direito à dignidade (18).

"A violência doméstica, como um fenômeno complexo, integra uma vasta gama de componentes relacionais que são pautados em vínculos subjetivos construídos socioculturalmente, por meio dos diversos modos de comunicação específicos. As relações travadas nestes contextos refletem a situação de desigualdade e a assimetria que conformam as relações de poder estabelecidas. O espaço privado, isto é, a esfera doméstica, mesmo que seus contornos não sejam monoliticamente definidos e a sua abrangência abarque sentidos além dos territoriais incluindo-se questões representativas, simbólicas, subjetivas e objetivas 
-, constitui uma importante tessitura implicada a outras construções societárias. Esta estruturação define o habitus incorporado e o exercício de poder estabelecido, muitas das vezes, com a supressão de autonomia e extinção dos limites de alteridade de outros membros” (19).

Para muitos pensadores, como o filósofo utilitarista John Stuart Mill, caberia à sociedade garantir os meios para que o homem se realizasse como pessoa alcançando sua felicidade (20). Um indivíduo nas condições de vulnerabilidade própria da infância, que foi violentado física e moralmente, precisará de um acompanhamento apropriado dessa sociedade para não apresentar sequelas significativas que dificultem sua realização como cidadão na idade adulta.

A relação sexual que é aceita como moralmente lícita na sociedade, tendo em vista a anuência dos envolvidos, não é moralmente aceita quando as partes carecem da capacidade de consentir espontaneamente ao ato sexual. É isto que normalmente acontece no abuso sexual intrafamiliar de menores, onde pode ocorrer coação explícita uso de força ou ameaça -, ou suspeita de compulsão - chantagem ou engano (8).

O silêncio da vítima, que tem a palavra confiscada pelo agressor, e a cumplicidade dos parentes não agressores, que se omitem de qualquer ação de proteção à vítima ou denúncia do agressor, são fatores que dificultam a solução desse conflito moral que assola e envergonha nossa sociedade (11).

Nessa relação vemos a criança sendo coisificada, usada apenas como meio para que o adulto consiga seus propósitos. Ela não é considerada como fim em si própria ou como pessoa. O que nos reporta ao filósofo deontologista prussiano, Imanuel Kant (21), que em sua obra famosa Fundamentação da Metafísica dos Costumes, no século 18, já chamava a atenção para o respeito que se deve ter com o ser humano: "os seres racionais são chamados de pessoas porque a sua natureza os diferencia como fins em si mesmos, quer dizer, como algo que não pode ser usado somente como meio e, portanto, limita nesse sentido todo capricho e é um objeto de respeito" (21).

Relembrando os considerados princípios canônicos da ética ocidental (autonomia, beneficência, não maleficência e justiça), propostos por Beauchamp e Childress em 1979, podemos afirmar que estes são feridos quando ocorre a violência sexual em crianças e adolescentes, haja vista os princípios se disporem não apenas às questões filosóficas, mas também à resolução de dilemas morais imediatos (22).

Corroborando Morales e Schramm (8), pode-se afirmar que os princípios hipocráticos de beneficência e não-maleficência não são respeitados na relação de abuso sexual contra menores não consencientes, pois o prejuízo quer físico, quer moral acontece. O princípio da justiça, concordando ainda com os autores, não tem espaço 
na relação, pois existe uma situação assimétrica de poder do adulto para com o menor. E o respeito à autonomia não existe já que a criança, também em função da assimetria constitutiva da relação adulto/ menor, não pode ou não sabe exercê-la.

O menor agredido torna-se duplamente vulnerável. Se denúncias são feitas, esse menor pode se tornar vítima não apenas do adulto agressor, mas também do sistema que buscará averiguar a veracidade das denúncias. Na legislação atual, observa-se uma preocupação maior na punição do culpado do que em todo o processo de sofrimento da vítima. Durante essa busca pelos responsáveis e culpados, a vítima (o menor) revive com intensidade os sentimentos de ansiedade, angústia, medo, raiva e vergonha da época em que sofria o abuso - revitimização (24).

Lembrando que, no caso da agressão intrafamiliar, o acusado é alguém da família ou próximo da vítima, quando esta criança consegue externar o que vivenciou, frequentemente passa a experimentar um sentimento de culpa, pois sai da condição de vítima e passa à condição de culpada pelos fatos ocorridos com ela. Muitas vezes, a solução paliativa dada é a retirada da criança de seu ambiente familiar, enquanto o agressor continua usufruindo desse ambiente (11). Esse afastamento pode dificultar a recuperação do vitimizado, pois ele poderá ir para abrigos onde não terá o vínculo afetivo familiar. O afastamento da criança do convívio familiar pode gerar nova sobrecarga emocional.

É necessário que se faça uma reflexão sobre a assistência dada às crianças e adolescentes durante o processo da busca dos culpados e após os menores terem sofrido violência e abuso sexual. $\mathrm{O}$ abuso sexual infantil é um problema que envolve duas facetas: a busca e punição do culpado e as questões legais envolvendo a proteção à criança e seu tratamento psicológico para que ela consiga administrar o trauma vivido (11).

É importante ressaltar que, no momento em que não há igual consideração dos interesses e das possibilidades de reparação de danos causados durante e após a agressão, ferem-se dois princípios básicos fundamentais que constituem a estrutura moral da justiça: o princípio da igualdade e o da equidade (8).

Deve-se refletir sobre as ações dos grupos não governamentais e governamentais que trabalham para minimizar os efeitos da violência sofrida pelas crianças e adolescentes. Infelizmente essas ações têm-se demonstrado muito tímidas ou quase inexistentes, sendo necessárias políticas no plano nacional e internacional que visem garantir a proteção à vulnerabilidade da criança e adolescente vítimas de abuso sexual.

A Convenção de Genebra desde 1934 estabeleceu, internacionalmente, o direito da criança e do adolescente, o que foi corroborado pela Convenção Internacional das Nações Unidas em 1989.

O Princípio $2^{\circ}$ da Declaração dos Direitos da Criança da Unesco, de 1959, também afirma que "a criança gozará de proteção especial e ser-lhe-ão proporcionadas 
oportunidades e facilidades, por lei e por outros meios, a fim de lhe facultar o desenvolvimento físico, mental, moral, espiritual e social, de forma sadia e normal e em condições de liberdade e dignidade. $\mathrm{Na}$ instituição de leis visando este objetivo levar-seão em conta sobretudo, os melhores interesses da criança” (25).

Infelizmente estes documentos se mostraram ineficazes para evitar abusos contra estes direitos. É mister que sejam propostas políticas públicas que possam proteger o menor e seus direitos de uma forma integral, quer o direito de não ser agredido, quer o direito de ser adequadamente tratado quando a agressão acontece, enquanto o culpado, normalmente seu parente, cumpre a pena imposta pela justiça. Aqui aparecem as redes de proteção aos menores.

A necessidade dessas redes de proteção é o grande desafio dos municípios, que têm que buscar a efetiva operacionalização das políticas voltadas para a infância, conforme o estabelecido pelo ECA. Estas redes potencializam a atuação mais abrangente e multidisciplinar de um conjunto de atores de diversas instituições que têm o mesmo foco temático na consecução da política de atendimento aos direitos da criança e do adolescente.

Este trabalho, além de aumentar a capilaridade das ações, tem muitas outras vantagens, tais como a troca e o acúmulo de experiências e de conhecimentos; a difusão e disseminação da atuação para áreas mais remotas e; a articulação com os trabalhos já existentes. A construção das redes exige habilidade, flexibilidade e persistência, devendo atuar no sentido de garantir os direitos das crianças e dos adolescentes, oportunizando os atendimentos psicológico, social e jurídico (7).

\section{Conclusão}

Com o crescente aumento da violência e do abuso sexual contra as crianças e os adolescentes, é preciso que se reflita também de maneira crescente sobre o assunto.

As ações existentes ainda são deficientes tanto em quantidade, quanto em qualidade. Sabe-se que ainda não se alcançou uma reflexão que considere aspectos éticos como o respeito à autonomia, a vulnerabilidade, os princípios da equidade e da igualdade, que resguardem a dignidade e a integridade do indivíduo.

Não se pode aceitar ou compactuar com o aprisionamento cruel e desumano sofrido por estes menores no momento em que são colocados como objeto de satisfação daqueles que deveriam, por questões éticas, legais e/ou afetivas, preservar a sua integridade.

Embora todas as previsões que estão elencadas no ECA, que completou 20 anos em 2010, há muito o que se corrigir na prática, onde não há o respaldo necessário 
para o cuidado da criança e do adolescente enquanto indivíduo possuidor de dignidade. São necessárias não apenas mudanças normativas, uma vez que já existem normas que regulem esta proteção, mas sim uma mudança estrutural em todos os âmbitos, uma mudança que garanta a essas crianças e adolescentes a segurança de que necessitam para seu crescimento, com o auxilio de profissionais interdisciplinares, unindo suas teorias e saber à práxis.

Todo o quadro de violência conhecido hoje no contexto mundial e nacional teve a sua origem nos primórdios da história e foi inserido em nossa cultura. Porém, cabe ressaltar que isto não se justifica nem se aceita, modernamente, pois a cultura é mutável e "os dilemas éticos acompanham o trilhar da história dos homens, uma vez que advêm de suas ações" (15). É importante a constante vigilância das consequências reveladas até aqui, para que ocorram ações futuras que minimizem a atual situação.

Para o efetivo acompanhamento das vítimas, faz-se necessária a formação de grupos de apoio multidisciplinares. Esse apoio deve ser oferecido por órgãos governamentais, em todas as esferas do poder, estabelecendo-se uma eficaz rede de proteção infantil. A vítima tem direito ao pleno atendimento garantido por lei e faz jus ao acompanhamento psicológico por tempo indeterminado, com o objetivo de minimizar as sequelas físicas ou psicológicas deixadas por ocasião do período de agressão. Acompanhamentos como estes que, infelizmente, não ocorrem com a eficácia desejada, mas que são imprescindíveis para a saúde física e mental do menor, pois permitem que o jovem possa, ao crescer, assumir seu papel na sociedade vivendo a plenitude de sua cidadania.

\section{Referências}

1- Faleiros VP, Faleiros ES, organizadores. Formação de Educadores: subsídios para atuar no enfrentamento à violência contra crianças e adolescentes. Brasília: MEC/SECAD; 2006. 2- Weiss J. Paidéia e politéia em Aristóteles. Biblos. 2004;16:167-75.

3- Platão. A República. São Paulo: Martin Claret; 2001.

4- Ariés P. História social da criança e da família. 2. ed. Rio de Janeiro: LTC; 1981.

5- Priore MD, organizador. História das crianças no Brasil. 2.ed. São Paulo: Contexto; 2000.

6- A roda [Internet]. São Paulo: Irmandade da Santa Casa de Misericórdia [citado em 13 dez. 2010]. Disponível em: http://www.santacasasp.org.br/roda.htm.

7- Santos BR. Métodos para a identificação de sinais de abuso e exploração sexual de crianças e adolescentes. 2 ed. Brasília: Secretaria Especial dos Direitos Humanos e Ministério da Educação; 2004.

8- Morales AE, Schramm FR. A moralidade do abuso sexual intrafamiliar em menores. Ciênc. saúde coletiva. 2002; 7(2):265-73.

9- Souza ER, Jorge MHPM. Impacto da violência na infância e adolescência brasileira: 
magnitude da morbimortalidade. In: Lima CA, organizadora. Violência faz mal à saúde. Brasilia: Ministério da Saúde; 2006. p. 23-28.

10- Monteiro Filho L, Phebo LB, organizadores. Maus tratos contra crianças adolescentes: proteção e prevenção - Guia de Orientação par profissionais de saúde. Petrópolis: Abrapia/ Autores Associados; 1997.

11- Araújo MF. Violência e abuso sexual na família. Psicol. estud. 2002;7(2):3-11 [citado 10 dez. 2010]. Disponível em: http://dx.doi.org/10.1590/S1413-73722002000200002.

12- Perrone R, Nannini M. Violence et abus sexuels dans la famille - une approche systémique et commmunicationnelle. Paris: ESF Éditeur; 1995.

13- Nogueira SD. Pedofilia e tráfico de menores pela internet: o lado negro da web. Âmbito Jurídico. 2001; 2(6):s.n. [citado em 13 dez. 2010] Disponível em: http://www.ambitojuridico. com.br/site/index.php?n_link=revista_artigos_leitura\&artigo_id $=5556$.

14- Pfeiffer L, Salvagni EP. Visão atual do abuso sexual na infância e adolescência. J Pediatr. 2005; 81(supl. 5):195-204 [citado em 13 dez. 2010]. Disponível em: http://dx.doi. org/10.1590/S0021-75572005000700010.

15- Clotet J, Feijó A. Bioética: uma visão panorâmica. In: Clotet J, Feijó A, Oliveira MG, organizadores. Bioética: uma visão panorâmica. Porto Alegre: Edipucrs; 2005. p.9-21.

16- Reich WT, editor. Encyclopedia of bioethics. New York/London: The Free Press/Collier MacMillan Publishers; 1995.

17- Miranda G. Bioética e eutanásia. São Paulo: Edusc; 2000.

18- Ferreira L. A Bioética e o Estatuto da Criança e do Adolescente. Justitia. 2001; 63(195):1019 [citado em 28 jan. 2008]. Disponível em: http://www.justitia.com.br/revistas/853y3b.pdf.

19- Barros NV. Violência intrafamiliar contra criança e adolescente - Trajetória histórica, políticas sociais, práticas e proteção social. [tese] Rio de Janeiro (RJ): Pontifícia Universidade Católica do Rio de Janeiro; 2005.

20- Mill JS. El Utilitarismo: un sistema de la lógica. Madrid: Alianza Editorial; 1997.

21. Kant I. Fundamentação da metafísica dos costumes. São Paulo: Abril Cultural; 1980.

22. Beauchamp TL, Childress JF. Principles of biomedical ethics. $4^{\text {th }}$ ed. New York: Oxford University Press; 1994.

23. Werlang BSG, Macedo MMK. Comportamento violento: uma questão para a bioética. In: Argimon IIL, Gauer GJC, Oliveira MS, organizadores. Bioética e Psicologia. Porto Alegre: Edipucrs, 2009. p. 67-88.

24. Trindade J. Manual de Psicologia Jurídica para operadores do Direito. Porto Alegre: Livraria do Advogado; 2004.

25. Organização das Nações Unidas (ONU). Declaração dos Direitos da Criança [internet]. 1959 [citado em 01 nov. 2012]. Disponível: http://198.106.103.111/cmdca/downloads/ Declaracao_dos_Direitos_da_Crianca.pdf 